\title{
SOSIALIASI HAK CIPTA DAN HAK MEREK PADA KELOMPOK USAHA KECIL DAN MENENGAH (UKM) SEBAGAI ASET BISNIS DI ERA INDUSTRI KREATIF

\author{
(Sosialisasi Hak Merek dan Hak Paten Pada Masyarakat Kecamatan Ciawigebang \\ Kabupaten Kuningan)
}

\author{
Haris Budiman, Bias Lintang Dialog dan Ratna Sayida \\ Fakultas Hukum Universitas Kuningan, Indonesia \\ E-mail : haris.budiman@uniku.ac.id
}

\begin{abstract}
The existence of UKM in Kuningan Regency is very diverse not only in the form of traditional foods of Kuningan but also spread in various creative businesses. That the Government's policy is clear, as of December 31, 2015 has opened the MEA or the Asean Economic Community, so that it has an impact on the circulation of trade traffic that will involve various countries and crossing national borders, including possibly coming to Kuningan, will enter foreign entrepreneurs to join in the competition with existing SMEs. The problem discussed is how to increase the legal awareness of small business actors on trademark rights and copyrights, as well as what efforts can be done by the government in giving legal protection to small and medium business groups. The method used is to provide socialization, legal counseling and mentoring of trademark rights and copyright. The results of the counseling revealed that the community's legal awareness of copyright and brand rights is still low therefore there needs to be legal protection measures for SMEs in Kuningan Regency. Therefore carried out socialization and legal counseling to SMEs in Kuningan Regency, regarding Intellectual Property Rights (IPR) especially about the importance of protecting the brand and reputation of the company by registering the trademark or patent rights in accordance with the mechanism of the Act. Legal protection must be done because the Copyright Act and Trademark rights regulate that registration of trademark rights uses the First To File system instead of the First To Inventory, meaning that who first registers will be served and protected by the law.
\end{abstract}

Keywords: Legal Protection, Trademark Rights, Copyright

\begin{abstract}
Abstrak
Keberadaan UKM di Kabupaten Kuningan sangat beragam tidak saja dalam bentuk makanan-makanan tradisional khas Kuningan tapi juga tersebar dalam berbagai usaha kreatif. Bahwa Kebijakan Pemerintah jelas, per 31 Desember 2015 telah dibuka MEA atau Masyarakat Ekonomi Asean, sehingga berdampak pada peredaran lalulintas perdagangan yang akan melibatkan berbagai Negara dan melintasi batas-batas Negara, termasuk mungkin akan datang ke Kuningan, akan masuk para pengusaha asing untuk ikut berkompetisi dengan para UKM yang telah ada. Permasalahan yang dibahas adalah bagaimana meningkatkan kesadaran hukum para pelaku usaha kecil terhadap hak merek dan hak cipta, serta upaya apa yang bisa dilakukan oleh pemerintah dalam memeberikan perlindungan hukum kepada kelompok usaha kecil dan menengah. Metode yang digunakan adalah dengan memberikan sosialisasi, penyuluhan hukum dan pendampingan pendafaptaran hak merek dan hak cipta. Hasil penyuluhan mengemukakan bahwa kesadaran hukum masyarakat terhadap hak cipta dan hak merek masih rendah oleh karena itu perlu ada upaya perlindungan hukum bagi para UKM yang ada di Kaupaten Kuningan. Oleh karena itu dilakukan sosialisasi dan penyuluhan hukum kepada para UKM yang ada di Kabupaten Kuningan,mengenai Hak Kekayaan Intelektual (HKI) khususnya tentang pentingnya menjaga merek dan reputasi perusahaan dengan mendaftarakan merek atau hak patennya sesuai dengan mekanisme Undang Undang. Perlindungan hukum harus dilakukan karena Undang Undang Hak Cipta dan hak Merek mengatur bahwa pendaftaran Hak merek menggunakan system First To File bukan First To Invent, artinya siapa yang pertama kali mendaftar itulah yang akan dilayani dan dilindungi oleh udang undang.
\end{abstract}

Kata kunci : Perlindungan Hukum, Hak Merek, Hak Cipta

\section{PENDAHULUAN}

Perkembangan dan kemajuan Teknologi Informasi yang demikian pesat telah menyebabkan perubahan kegiatan kehidupan manusia dalam berbagai bidang yang 
secara langsung telah mempengaruhi lahirnya bentuk-bentuk perbuatan hukum baru, penggunaan dan pemanfaatan Teknologi Informasi harus terus dikembangkan untuk menjaga, memelihara, dan memperkukuh persatuan dan kesatuan nasional berdasarkan Peraturan Perundang-undangan demi kepentingan nasional, bahwa pemanfaatan Teknologi Informasi berperan penting dalam perdagangan dan pertumbuhan perekonomian nasional untuk mewujudkan kesejahteraan masyarakat ${ }^{1}$.

Setelah Indonesia meratifikasi Persetujuan Pendirian Organisasi Perdagangan Dunia (WTO) melalui Undang Undang Nomor 7 tahun 1994, maka Indonesia terikat dan diwajibkan untuk mengharmonisasi hukumnya terkait dengan persetujuan ini. Dalam hal ini Idonesia wajib mengundangkan Hak Atas Kekayaan Intelektual (HAKI). Hak Kekayaan Intelektual (HKI) merupakan hasil kreatifitas intelektual berupa ide, penemuan dan ekspresi kreatif yang terkadang disebutnya dengan "produk pemikiran" atau "asset intelektual". Karena sangat jelas bahwa hak kekayaan intelektual merupakan hak yang lahir dari kemampuan intelektualitas seseorang.

Namun demikian, harus diakui, bagi Indonesia dan juga negara-negara berkembang lainnya, kesadaran masyarakat tentang HKI sendiri masih rendah. Bukti yang dapat dikemukakan adalah masih rendahnya pendaftaran HKI oleh kreator domestik serta banyaknya pelanggaran HKI oleh masyarakat. Sejalan dengan itu, diakui pula bahwa sistem HKI yang saat ini dikembangkan belum mengarah kepada sistem perlindungan dan pengelolaan HKI yang dapat memberikan nilai guna dan daya guna bagi Perguruan Tinggi. Harapan sistem HKI dapat memberikan manfaat yang tentunya tidak sekedar mengharapkan peran aktif dari pemerintah tetapi Perguruan Tinggi pun harus berani menyusun program kerja guna perlindungan dan pengelolaan HKI mereka. Secara nyata upaya optimalisasi Perguruan Tinggi dalam perlindungan dan pengelolaan HKI di Perguruan Tinggi dilakukan melalui tiga bentuk program kerja pokok, yakni : penyadaran HKI bagi civitas akademis di Perguruan Tinggi, perlindungan hukum terhadap HKI bagi hasil karya intelektual di lingkungan Perguruan Tinggi, dan pemanfaatan HKI serta pengelolaan atas hasil karya intelektual di lingkungan Perguruan Tinggi sehingga perguruang tinggi berperan dalam meningkatkan pengetahuan masyarakat khususnya dalam kesadaran hukum ${ }^{2}$. Sebagai Kabupaten dengan potensi kekayaan intelektual yang melimpah terutama di bidang industri kreatif, Kabupaten Kuningan sudah saatnya melakukan pendampingan dan perlindungan hukum bagi usaha tersebut. Oleh karena itu keberadaan lembaga yang melayani Hak atas Kekayaan Intelektual sangat dibutuhkan oleh masyarakat. Berdasarkan hal ini, maka kami terpanggil untuk memberikan sosialisasi penyuluhan hukum dan pendampingan pendaftaran hak kekayaan intelektual berupa Hak Cipta dan Hal Merek pada para

\footnotetext{
${ }^{1}$ Suwari Akhmaddhian dan Asri Agustiwi. 2016. Perlindungan Hukum Terhadap Konsumen Dalam Transaksi Jual Beli Secara Elektronik Di Indonesia. Jurnal Unifikasi, ISSN 2354-5976 Vol. 3 No. 2 Juli 2016. 40-60.

${ }^{2}$ Suwari Akhmaddhian, Erga Yuhandra dan Gios Adhyaksa. 2018. Peningkatan Kesadaran Hukum Masyarakat Desa Windujanten, Kabupaten Kuningan, Indonesia. Empowerment : Jurnal Pengabdian Masyarakat, e-ISSN 2598-2052 Vol. 01 Nomor 01 Januari 2018. 16-22.
} 
pengrajin dan pengusaha kecil dan menengah agar bisa melindungi produk-produknya yang saat ini sudah berkembang di masyarakat. Berdasarkan dipaparkan di atas, maka dalam hal ini penulis ingin merumuskan permasalahan yang terjadi di Desa Geresik Kecamatan Ciawigebang Kabupaten Kuningan sebagai berikut:

1. Bagaimana meningkatkan kesadarah hukum bagi masyarakat di Desa Geresik Kecamatan Ciawigebang Kabupaten Kuningan dalam penggunaan hak merek dan hak cipta.

2. Bagaimana proses dan mekanisme pendaftaran Hak Merek dan Hak Cipta terhadap produk-produk yang dikembangkan oleh masyarakat.

\section{METODE PELAKSANAAN}

Kata metode berasal dari bahasa Yunani yaitu methodos yang berarti cara atau menuju suatu jalan. Metode merupakan kegiatan ilmiah yang berkaitan dengan suatu cara kerja (sistematis) untuk memahami suatu subjek atau objek penelitian, sebagai upaya untuk menemukan jawaban yang dapat dipertanggung jawabkan secara ilmiah dan termasuk keabsahannya. ${ }^{3}$ Metode ini digunakan untuk menyampaikan materi penyuluhan hukum bersifat kognitif namun dikemas dengan informasi yang menyenangkan. ${ }^{4}$ Selain itu metode pendekatan yang digunakan dalam Pengabdian Kepada Masyarakat ini melalui metode pendekatan workshop, ceramah kemudian diakhir acara diadakan tanya jawab, dengan tanya jawab ini masyarakat diberikan kesempatan untuk bertanya sesuai dengan tema penyuluhan, atau masyarakat dapat bertanya di luar tema yang telah ditentukan.

\section{HASIL DAN PEMBAHASAN}

1. Upaya meningkatkan kesadarah hukum dalam penggunaan hak merek dan hak cipta.

Upaya meningkatkan kesadarna hukum bagi masyarakat di desa Geresik Kecamatan Ciawigebang Kabupaten Kuningan dalam menggunakan hak kekayaan intelektualnya didasarkan pada permasalahan yang terjadi dapat digambarkan sebagai berikut :

a. Lemahnya kesadaran hukum masyarakat

Bagi masyarakat di desa, hak merek dan hak cipta merupakan hal baru. Mereka belum memahami secara luas, sehingga proses pengurusan hak kekayaan seperti itu merupakan pemborosan yang membutuhkan biaya yang sangat besar. Padahal hak merek dan hak cipta pada dasarnya merupakan asset yang menjadi mutlak bagi pihak-pihak terkait untuk melakukan proteksi dan pengelolaan atas kekayaan intelektual yang dimiliki masyarakat. Upaya

3 Rosady Ruslan, Metode Penelitian Public Relations dan Komunikasi, Rajawali Pers, Jakarta, 2003, hlm. 24.

4 Endang Purwaningsih, dkk. Penyuluhan Hukum Informasi dan Transaksi elektronik Bagi Para Guru dan Siswa SDN 05 Cempaka Baru Kemayoran Jakarta Pusat, Jurnal ABDIMAS UNMER Malang, Vol. 3 Desember 2018. 
proteksi dan pengelolaan atas hak cipta dan hak merek yang dilakukan oleh tim pengabdian pada masyarakat diharapkan akan memberikan dampak bagi keberlanjutan produk-produk yang dihasilkan masyarakat. Selain itu, apabila terjadi pelanggaran-pelanggaran hak cipta dan hak merek yang dimiliki masyarakat menjadi tidak diperhatikan bahkan tidak dapat terlindungi secara hukum. Hal ini tentu hendaknya dapat disikapi oleh Perguruan Tinggi dan pemerintah dengan cara menyusun kesadaran hukum yang berkenaan dengan perlindungan dan pengelolaan hak cipta dan hak merek. Kesadaran hukum akan hak cipta dan hak merek harus dapat menguatkan keberadaan dari perlindungan dan pengelolaan yang dilakukan oleh pemerintah.

b. Minimnya tingkat pengetahuan masyarakat atas masalah Hak Merek dan Hak Cipta

Hingga kini Hak Merek dan Hak Cipta masih dianggap sesuatu yang baru bagi masyarakat. Anggapan ini tentunya tidak dapat disalahkan. Hak merek dan hak cipta adalah merupakan konsep yang dilahirkan dari paham individualistis. Dengan kenyataan ini, maka wajarlah apabila masyarakat banyak yang belum tahu dan mengerti tentang konsep kekayaan intelektual. Dengan hal demikian, maka perlu kiranya dilakukan suatu bentuk peningkatan pengetahuan masyarakat terhadap masalah hak cipta dan hak merek. Apabila melihat pada prakteknya, pemberian pengetahuan sering dilaksanakan dengan mengandalkan lembaga pemerintah maupun swasta dan hal tersebut dilakukan kurang sistematis. Dari sini, tentunya Perguruan Tinggi patut memikirkan pola peningkatan pengetahuan masyarakat terhadap hak cipta dan hak merek secara lebih profesional lagi.

c. Minimnya informasi dan data yang berkaitan dengan kepemilikan hak cipta dan hak merek

Pemerintah Daerah tidak memiliki data yang berkaitan dengan dengan hak cipta dan hak merek pada masyarakat. Minimnya informasi dan data disebabkan karena pemerintah daerah tidak merencanakan suatu penataan sistem database yang baik untuk asset hak kekayaan intelektual yang ada pada masyarakat.

d. Tidak adanya sistem pengawasan HKI di masyarakat secara efektif

Salah satu tidak adanya perlindungan HKI milik maswyarakat disebabkan tidak adanya suatu sistem pengawasan HKI yang efektif. Untuk bagian-bagian HKI, seperti merek, paten, desain industri dan desain tata letak sirkuit terpadu pengawasan nampaknya sangat bergantung pada si pemegang HKI. Akibat dari hal demikian, sangat jelas pemegang HKI sangat terbatas dan lemah untuk melakukan pengawasan terhadap HKI. Atas dasar itu sudah saatnyalah apabila Perguruan Tinggi secara proaktif melakukan upaya dalam bentuk penyiapan sistem pengawasan HKI yang pada akhirnya akan memberikan kemanfaatan baik bagi pemegang hak, civitas akademis maupun bagi masyarakat secara luas. 
e. Minimnya tingkat pemanfaatan HKI oleh masyarakat untuk meningkatkan kapasitas usahanya

Masalah terakhir dalam bidang HKI ini nampaknya merupakan masalah yang saat ini sepertinya lepas dari perhatian pemerintah. HKI bagi beberapa kalangan Perguruan Tinggi hanya identik dengan perlindungan melalui cara pendaftaran, setelah dianggap semuanya selesai. Padahal, dalam konteks manajemen HKI, perlindungan HKI hanyalah satu aspek saja, aspek lainnya yaitu melakukan pemanfaatan HKI. Pemanfaatan HKI yang dimaksudkan dapat dilakukan untuk kepentingan komersial dan dapat juga sifatnya non komersial. Tetapi yang jelas dengan adanya pemanfaatan HKI ini harapannya ada dampak yang akan dirasakan oleh masyarakat

Solusi yang kami tawarkan terkait permasalahan di atas, yang dapat dijadikan sebagai bahan pertimbangan yaitu sebagai berikut:

1. Menyelenggarakan Penyuluhan Hukum : sebagai awal dari kegiatan ini adalah diberikan pemahaman kepada masyarakat tentang konsekuensi diberlakukannya Undang Undang Hak Cipta dan Undang Undang Hak Merek terhadap penggunaan Merek dan Ciptaan yang telah didaftarkan.

2. Regulasi Pemerintah Daerah : Pemerintah Daerah harus membuat regulasi untuk melindungsi para pengusaha yang tergolong dalam usaha kecil dan menengah (UKM) untuk menjaga dan melindungi hak kekayaan intelektual yang ada dan berkembang di masayrakat terutama pada para pengusaha dan pengrajin yang tergolong dalam usaha kecil dan memengah.

3. Peran Serta Masyarakat : peran serta masyarakat untuk ikut serta melindungi merek dagang dan ciptaannya sangat diperlukan, karena masyarakat memiliki dua peran, yaitu sebagai penghasil produk dan pengguna produk. Oleh karena itu tingkat partisipasi masyarakat terhadap pemahaman hak kekayaan intelektual sangat diperlukan.

4. Pendampingan Pendaftaran Hak Cipta dan Hak Merek : mendampingi masyarakat untuk mendaftarakan hak cipta dan hak merek kepada Kementerian hukum dan HAM agar bisa terbit Sertifikat hak Kekayaa intelektual terhadap merek atau ciptaan dagang yang berkembang di masyarakat.

5. Melakukan Kerjasana dengan Pusat Layanan Hak Kekayaan Intelektual (PUSHAKI) Universitas Kuningan : mendorong Pemerintah Desa Geresik Kabupaten Kuningan untuk melakukan kerja sama denagn PUSHAKI Universitas Kuningan terkait perlindungan Usaha Kecil dan Menengah agar masyarakat bisa terlindungi.

2. Proses dan mekanisme pendaftaran Hak Merek dan Hak Cipta terhadap produkproduk yang dikembangkan oleh masyarakat.

Kegiatan penyuluhan hukum menitikberatkan pada bagaimana proses dan mekanisme pendaftaran yang bisa dilakukan masyarakat terhadap produk-produk 
yang akan didaftarkan hak cipta dan hak mereknya. Tahapannya adalah dengan mendatangi Pusat Kekayaan Intelektual di Universitas Kuningan, untuk selanjutnya dilakukan pendampingan. Target luaran yang akan dihasilkan dari masing-masing solusi di atas yaitu sebagai berikut:

1. Dengan diadakannya sosialisasi tersebut diharapkan masyarakat di desa Geresik memiliki pengetahuan dan pemahaman terhadap penggunaan Hak Merek dan Hak Cipta terhadap usahanya.

2. Diharapkan meningkatnya partsispasi masyarakat setempat terhadap pentingnya pengunaan Hak Merek dan hak Cipta yang sudah dilindungi menurut ketentuan peraturan perundang-undangan.

3. Diharapkan masyarakat dapat mendapatkan informasi yang lebih komprehensif tentang hak atas kekayaan intelektual.

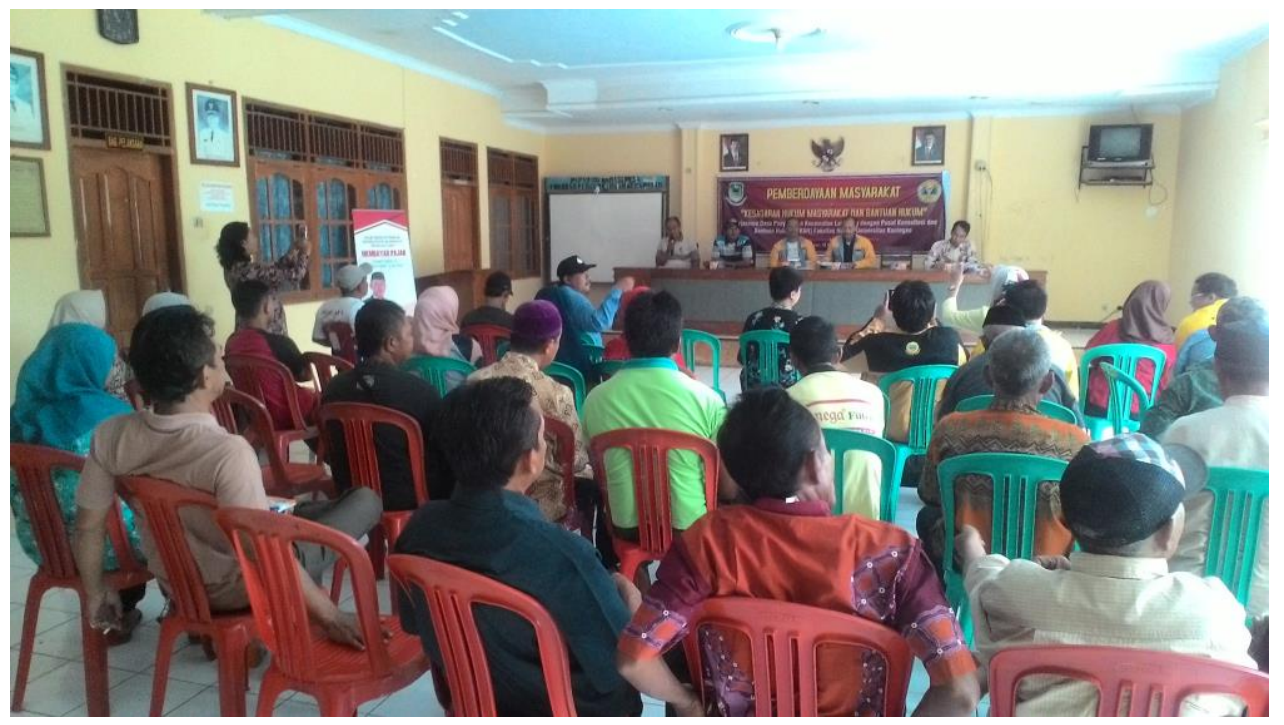

Gambar : Kegiatan pemberdayaan masyarakat

\section{SIMPULAN}

Berdasarkan pengamatan selama melakukan pengabdian masyarakat pada warga masyarakat terutama para pelaku UKM di desa Geresik Kabupaten Kuningan, tim memperhatikan antusiasme peserta dalam kegiatan sosialisasi ini. Hal ini terlihat dari banyaknya pertanyaan yang diajukan dan keinginan untuk mendapatkan pendampingan baik untuk mendapatkan hak merek maupun hak cipta dari produk-produk yang mereka hasilkan. Masyarakat mulai menyadari akan pentingnya hak-kekayaan intelektual untuk melindungi dan menjaga produk yang sudah susah payah dirintis agar tidak dimanfaatkan oleh pihak lain.

\section{SARAN}

Tim pengabdian memberikan saran agar kegiatan sosialisasi tentang Undang Undang Hak Cipta dan Undang Undang Hak Merek harus lebih ditingkatkan lagi terutama untuk kelompok-kelompok UKM yang mulai menjamur di masyarakat sebagai 
salah satu upaya pemberdayaan menuju ketahanan ekonomi yang semakin kuat dan mandiri.

\section{UCAPAN TERIMA KASIH}

Kami ucapkan terima kasih kepada Lembaga Penelitian dan Pengabdian Kepada Masyarakat Universitas Kuningan, Kelompok Ibu-Ibu PKK, dan semua pihak yang telah membantu pelaksanaan kegiatan pengabdian ini.

\section{DAFTAR PUSTAKA}

Anis Mashdurohatun, 2016, Mengembangkan Fungsi Sosial Hak Cipta Indonesia: UNS Press, Surakarta

Rosady Ruslan, Metode Penelitian Public Relations dan Komunikasi, Rajawali Pers, Jakarta, 2003,

Suwari Akhmaddhian dan Asri Agustiwi. 2016. Perlindungan Hukum Terhadap Konsumen Dalam Transaksi Jual Beli Secara Elektronik Di Indonesia. Jurnal Unifikasi, ISSN 2354-5976 Vol. 3 No. 2 Juli 2016. 40-60.

Suwari Akhmaddhian, Erga Yuhandra dan Gios Adhyaksa. 2018. Peningkatan Kesadaran Hukum Masyarakat Desa Windujanten, Kabupaten Kuningan, Indonesia. Empowerment : Jurnal Pengabdian Masyarakat, e-ISSN 2598-2052 Vol. 01 Nomor 01 Januari 2018. 16-22.

Undang Undang Nomor 19 Tahun 2002 tentang Hak Cipta

Undang Undang Nomor 20 Tahun 2016 tentang Merek dan Idikasi Geografis 